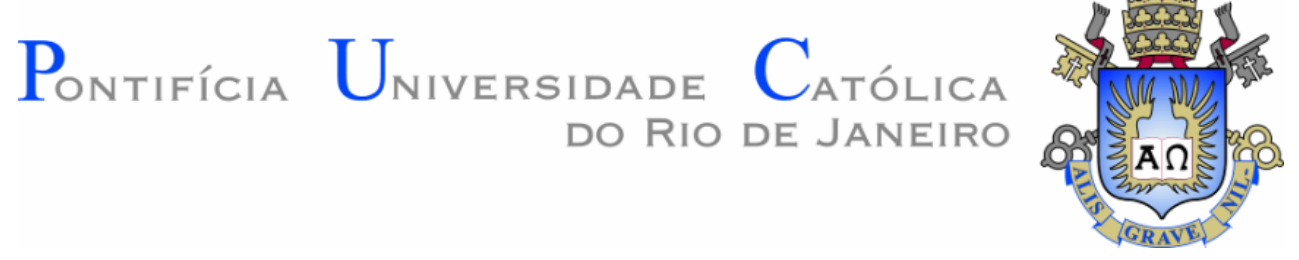

Pedro Eugênio Gomes Pazelli

\title{
A utilização da animação no Ensino Fundamental para a Educação em Saúde
}

Dissertação apresentada como requisito parcial para obtenção de grau de Mestre pelo Programa de Pósgraduação em Design do Departamento de Artes \& Design da PUC-Rio.

Orientadora: Prof. Luiza Novaes 
Pedro Eugênio Gomes Pazelli

\title{
A utilização da animação no Ensino Fundamental para a Educação em Saúde
}

Dissertação apresentada ao Programa de Pós-Graduação em Design da PUC-Rio, como requisito parcial para obtenção do grau de Mestre em Design. Aprovada pela Comissão examinadora abaixo assinada.

\author{
Profa. Luiza Novaes \\ Orientadora \\ Departamento de Artes \& Design \\ Profa. Jackeline Lima Farbiarz \\ Departamento de Artes \& Design
}

Prof. Adilson Vaz Cabral Filho Universidade Federal Fluminense - UFF

Prof ${ }^{a}$. Denise Berruezo Portinari Coordenadora Setorial do Centro de Teologia E Ciências Humanas - PUC-Rio

Rio de Janeiro, 03 de abril de 2012 
Todos os direitos reservados. É proibida a reprodução total ou parcial do trabalho sem a autorização da universidade, do autor e da orientadora.

\section{Pedro Eugênio Gomes Pazelli}

Graduou-se em Comunicação Social - Publicidade pelo Centro Universitário da Cidade e especializou-se em Desenho de Animação pela PUC-Rio. Atua profissionalmente como técnico e facilitador de Educação Permanente em Saúde na Secretaria de Saúde da Prefeitura do Rio de Janeiro. Cria e produz desenhos de animação para a saúde pública, apostilas e textos. Algumas de suas animações sobre o tema Educação em Saúde fazem parte do acervo das videotecas da Fundação Oswaldo Cruz, TV Brasil, TV Globo, Vídeo Minas Saúde, Ministério da Saúde e Cinemateca de Bologna, na Itália. Publicou um livro sobre Educação em Saúde pela Agbook-SP e está com outro em vias de ser publicado em 2012 pela Interciências-Rio.

Ficha Catalográfica

Pazelli, Pedro Eugênio Gomes

A utilização da animação no ensino fundamental para a educação em saúde / Pedro Eugênio Gomes Pazelli ; orientadora: Luiza Novaes. -2012.

166 f. : il.(color.) ; $30 \mathrm{~cm}$

Dissertação (mestrado)-Pontifícia Universidade Católica do Rio de Janeiro, Departamento de Artes e Design, 2012.

Inclui bibliografia

1. Artes e design - Teses. 2. Animação. 3. Educação. 4. Educação em saúde. 5. Comportamento. I. Novaes, Luiza. II. Pontifícia Universidade Católica do Rio de Janeiro. Departamento de Artes e Design. III. Título. 
Dedico este trabalho ao Pe. Jesus Hortal Sánchez, S. J. e a minha esposa Sônia Maria da Cruz pelo incentivo que ambos me deram para a realização deste Mestrado, desde a época da minha Especialização em Animação. 


\section{Agradecimentos}

Aos professores Marcos Magalhães pelas primeiras orientações em desenho de animação.

A Professora Cláudia Bolshaw, que me incentivou a fazer o mestrado após a conclusão de minha Especialização em Animação na PUC-Rio.

À PUC-Rio, pelos auxílios concedidos, sem os quais este trabalho não poderia ter sido realizado.

À professora Luiza Novaes, minha orientadora, outra grande incentivadora que me adotou como seu orientando, me conduzindo sempre com prontidão, amizade e excelente bom humor, não se incomodando em momento algum com as minhas dúvidas. Uma verdadeira amiga.

Às professoras Rita Couto e Jackeline Farbiarz, pelo carinho.

Aos professores Adilson Cabral e Eula Cabral, professores da minha graduação, que muito me incentivaram neste percurso.

Aos meus amigos de trabalho que me deram ideias importantes que vieram a me ajudar na conclusão de meu Projeto de Pesquisa.

A minha mãe Edwiges pelo apoio que sempre me deu nos estudos 
Ao CCPG (Coordenação Central de Pós-graduação e Pesquisa).

A minha esposa Sônia Maria

A todos, muito obrigado. 


\section{Resumo}

Pazelli, Pedro Eugênio Gomes; Novaes, Luiza. A utilização da animação no Ensino Fundamental para a Educação em Saúde. Rio de janeiro, 2012. 166p. - dissertação de Mestrado - Departamento de Artes \& Design, Pontifícia Universidade Católica do Rio de Janeiro.

O trabalho discute a utilização da linguagem da animação nas escolas, como recurso de apoio ao ensino de várias disciplinas curriculares. Apresenta um estudo específico, realizado na área da Educação em Saúde, área que muitas vezes sofre indiferença ou resistência por parte dos alunos, acostumados a comportamentos poucos saudáveis em seu cotidiano. A pesquisa foi desenvolvida com foco em crianças do Ensino Fundamental em duas escolas da cidade do Rio de Janeiro. Animações sobre temas de Educação em Saúde foram adotados nas aulas, como recursos de apoio, para se verificar o impacto que produziam nos alunos. As ações saudáveis dos personagens, mostradas nas animações, foram recebidas de forma bastante positiva, a ponto de produzirem mudanças significativas no comportamento do público alvo.

\section{Palavras-chave}

Animação; educação; educação em saúde; comportamento. 


\section{Abstract}

Pazelli, Pedro Eugênio Gomes; Novaes, Luiza (Advisor). The use of animation for Health Education in Elementary School. Rio de janeiro, 2012. 166 p. - MSc. Dissertation - Departamento de Artes \& Design, Pontifícia Universidade Católica do Rio de Janeiro.

The dissertation discusses the use of animation language as educational resource to support teaching of various curricular subjects in schools. It presents a specific study conducted in the field of Health Education, a field that often suffers from indifference or resistance from students, accustomed to unhealthy practices in their daily lives. The research was developed with a focus on elementary school children, in two schools in the city of Rio de Janeiro. Animated videos addressing health education issues were selected and used in the classes, as support resources, to verify the impact they could produce on students. The healthy attitudes of the characters shown in the animated videos were received very positively, as to produce significant changes in the behavior of the target audience.

\section{Keywords}

Animation; education; health education; behavior. 


\section{Sumário}

1. Introdução 10

1.1. Diretriz metodológica e estrutura da dissertação 18

2. O Cinema e a Educação 21

2.1. A Animação-Linguagem, história e a motivação para as crianças 22

2.2. Animações para Educação no Brasil e no Mundo 29

3. O Projeto de pesquisa 38

3.1. O que se entende por saúde e Educação em Saúde 38

3.2. O PSE-Programa Saúde na Escola e a Educação em Saúde na Escola 41

3.3. A proposta de pesquisa em escolas; a escolha das escolas e do público alvo-justificativas $\quad 41$

4. O Estudo de Caso 48

4.1. Metodologia 48

4.2. O Questionário 1

4.3. Seleção preliminar das animações; escolha final
das animações para a pesquisa e planejamento das oficinas

4.4. A exibição das animações para os alunos $\quad 59$

4.5. As oficinas de reflexão 62

4.6. Os Questionários 2, 3 e 4

4.7. Análise de dados e elaboração de quadros síntese $\quad 70$

5. Considerações finais $\quad 79$

Referências Bibliográficas $\quad 83$

Sites Web apresentados $\quad 85$

$\begin{array}{ll}\text { Anexos } & 86\end{array}$ 